\title{
¿EL SMART VALLEY DEL SUR DE CATALUÑA? LA (RE)CONSTRUCCIÓN TECNOSIMBÓLICA DE TARRAGONA
}

Josep Puigbó Testagorda Doctorando en Antropología y Comunicación Universitat Rovira i Virgili Josep.puigbo@urv.cat

RESUMEN: El objetivo de este artículo es analizar el estado de las iniciativas Smart City en la ciudad de Tarragona realizando una especial atención a la construcción retórica en relación con el concepto. Se parte de una contextualización de las dos principales políticas involucradas en la transformación de Tarragona en una ciudad inteligente. Mediante el examen del caso concreto de la Tabacalera, una antigua fábrica industrial en proceso de reconversión smart, se pretende ofrecer una muestra de las contradicciones y problemáticas que afronta esta estrategia urbana.

PALABRAS CLAVE: smart city; urbanismo smart; tecnópolis; espacios industriales; gobernabilidad.

ABSTRACT: This article aims to analyze the state of smart city initiatives in Tarragona, focusing on the rhetorical construction of the concept. The article examines the city's main smart policies in order to understand the context of Tarragona's transformation into a smart city. As an example of the primary contradictions and problems involved in this kind of planning, this article focuses on the hypothetical smart renovation of an industrial factory (Tabacalera) in Tarragona.

KEYWORDS: smart city; smart urbanism; technopolis; industrial spaces; governability 
$\mathrm{D}$ EL NORTE AL SUR DEL PLANETA, se impone la noción de nuevas estrategias urbanas basadas en la tecnología como solución milagrosa a los problemas surgidos en la ciudad. Encontramos iniciativas, proyectos e intervenciones urbanas que usan la nomenclatura smart city (SC) en todos los rincones del planeta, «todas las ciudades quieren ser una ciudad inteligente hoy en día» (March y Ribera-Fumaz, 2014: 1).

La ciudad de Tarragona también se ve involucrada en esta tendencia. Este artículo ${ }^{1}$ pretende analizar la construcción del concepto SC en esta ciudad. Con una atención especial a su desarrollo retórico, se examinan las principales directrices políticas que dan contexto a la emergencia de la última moda en urbanismo.

Los objetivos del artículo se basan en el análisis de las principales estrategias políticas que permiten la emergencia y el inicio de la transformación de Tarragona en una SC. En este sentido, resulta necesario determinar los actores primordiales involucrados en este fenómeno, desde sus impulsores - bien sean públicos o privados - a los colectivos afectados por la hipotética smartización de la ciudad. Además, se pretende comprender y recoger las principales consecuencias y contradicciones vinculadas a la conversión de Tarragona en una ciudad inteligente.

Para dar respuesta a este último objetivo, el artículo se concentra en el caso de la Tabacalera, un antiguo espacio industrial objeto de intervención por parte de un consistorio local interesado en generar un emblema smart, aunque este no ha cumplido con los propósitos esperados, comportando la crítica ciudadana.

El texto se estructura a partir de una breve contextualización de las características económicas de Tarragona, seguida de una exposición de los principales postulados teóricos vinculados al concepto SC, para después centrarse en las dos políticas que dan sentido al inicio de los proyectos de ciudad inteligente en Tarragona: los Juegos Mediterráneos 2018 y el

I Esta aproximación forma parte de la realización del trabajo final del Máster en Antropología Urbana, Migraciones e Intervención Social, que lleva por título: «De la utopía retórica a la práctica distópica: la (re)construcción de ciudades del futuro en la disputa por la centralidad espacial». Quiero agradecer al Dr. Joan Josep Pujadas el asesoramiento prestado en la elaboración de este texto. 
Pla Tarragona 2022. Finalmente, se presentan y discuten las principales intervenciones smart en la ciudad y se dedica especial atención al caso de la Tabacalera como ejemplo representativo de las problemáticas que implican estas políticas.

La metodología empleada para afrontar los objetivos anteriores ha sido el análisis documental como base y fundamento de una investigación sociohistórica sobre la evolución de las iniciativas SC en Tarragona. Esto, en un proceso posterior a la definición del problema y como estadio previo a un hipotético abordaje de corte etnográfico.

El objetivo y finalidad de esta metodología ha sido la reconstrucción de procesos sociales en lo urbano, entendiendo las fuentes documentales como instrumentos para estudiar cambios cronológicos. Este método presenta ciertas ventajas, como su calidad de técnica no intrusiva, pero también inconvenientes, como la disposición limitada de documentos y el carácter secundario de las fuentes.

El tratamiento de los documentos se ha centrado en una aproximación de contenido temático, obviando aspectos semánticos, realizada mediante a) la recuperación de información, b) la categorización de la misma, dando lugar a documentos secundarios, para c) iniciar un proceso analítico donde la información es estudiada, interpretada y situada en su campo fenomenológico ${ }^{2}$.

El proceso de identificación, basado en la ubicación de antecedentes sobre el fenómeno y en la naturaleza de la documentación, ha tenido en cuenta la calidad técnica de las fuentes, su profundidad y enfoque. Mientras que los criterios de selección de las fuentes a incluir en el repertorio analítico se han basado en la autenticidad, veracidad y resonancia sobre la problemática. Sin desconsiderar la finalidad de la investigación, el futuro producto obtenido y su adecuación a los objetivos.

Por último, la compartimentación de documentos para la identificación ha dado lugar a categorías estructurantes de las fuentes de análisis. Estas, entendidas como unidades de registro, se han dividido en las siguientes clases: fuentes documentales locales (provenientes de medios de comunicación), fuentes académicas, fuentes institucionales (materiales de organismos oficiales) y fuentes técnicas (informes y similares). 


\section{La situación económica de Tarragona}

Resulta pertinente centrar, brevemente, las características de la ciudad de Tarragona en relación con su contexto económico y laboral, dado que la SC es presentada como una consecuencia urbana naturalizada de la inmersión en la sociedad de la información.

La ciudad de Tarragona, y su provincia aún sostienen fuertes dependencias con el sector industrial químico, portuario y el turismo de playa, más que con el sector de la innovación tecnológica. Con la excepción de la universidad local y las incursiones del sector (petro)químico en este ámbito.

La trazabilidad de este hecho reside en la tardía industrialización de Tarragona en los años sesenta. La industrialización se convirtió en el «[...] eje indiscutible de la economía de Tarragona ciudad, que se introducía en los mercados internacionales con el impulso de grandes multinacionales de la química y la energía como Dow, Hoechst, BASF o Bayer» (González Márquez, 2016: 62).

La repercusión que tuvo la industrialización representa «el mayor hito social y urbanístico de la ciudad, pues implicó la casi duplicación y diversificación de la población desde 1960 a 1981» (González Márquez, 2016: 62).

Actualmente, en la provincia de Tarragona, las principales actividades que destacan por su implementación y desarrollo, aparte del turismo, siguen vinculándose con la industria química, el puerto y el sector agroalimentario (SEPE, 2017). En cuanto al número de trabajadores por secciones de actividad, predominan tres ámbitos: comercio y reparación de vehículos (17,36\%), industria manufacturera (14,09\%) y actividades sanitarias-servicios sociales (8,39\%) (SEPE, 2017).

El aún fuerte peso de la industria tradicional y la dependencia de un turismo de playa que, pese a concentrarse especialmente en los núcleos costeros adyacentes a la ciudad, tiene una presencia significativa en la ciudad son indicadores de la presencia limitada de nichos laborales tecnológicos. Como veremos, este hecho debe servirnos de marco contextual en tanto que los promotores locales de la SC pretenden ubicar los agentes industriales tradicionales como instituciones punteras para la misma. 


\section{La incorporación del paradigma smart city en la agenda urbana global}

Los precedentes del concepto smart city se remontan a las primeras fórmulas urbanas de la economía informacional de principios de 1990, las tecnópolis, «formas específicas de concentración territorial de innovación tecnológica con un potencial para generar sinergia científica y una productividad económica» (Castells y Hall, 1994: 31).

Estas transformaciones suponen la modificación de un paisaje urbano industrial de fábricas y chimeneas por una ciudad de oficinas colaborativas. Evidenciándose un cambio económico y productivo que implica la transición de un Mánchester industrial hacia un Silicon Valley informacional.

La SC es la consecuencia directa de la transformación hacia un sistema económico impuesto por un mundo tecnologizado que reemplaza la economía industrial por la economía de la información (Rabari y Storper, 2014). Surge en un contexto de flexibilidad económica derivado de un mercado global más competitivo que apela a la necesidad de una ciudad igualmente competitiva (Kitchin, 2015; Glasmeier y Christopherson, 2015).

El concepto se introduce al mismo tiempo que las ciudades experimentan una profunda transformación estructural, «en el centro de tal transformación se encuentra una revolución tecnológica» (Borja y Castells, 1997: 21). La explosión tecnológica ofrece el marco necesario para el desarrollo de un urbanismo centrado en la tecnología (Glasmeier y Christopherson, 2015) que «vincula las transformaciones tecnológicas de la información con el desarrollo económico, político y social» (Hollands, 2008: 305).

Smith (2002) señala que las regiones industriales fueron la columna vertebral de los capitales nacionales en los siglos XIX y xx, pero ahora estas economías urbanas se transforman en plataformas de y para la producción global (Smith, 2002): «[...] esta rearticulación de la escala de la producción hacia la escala metropolitana es una expresión de un cambio global; y al mismo tiempo se encuentra en el centro de un nuevo tipo de urbanismo» (Smith, 2002: 257). 
La SC ilustra la intencionalidad de las ciudades para orientarse hacia este nuevo contexto global de competencia. Incluso entre aquellas regiones que aún presentan fuertes dependencias con el sector industrial tradicional, como el Camp de Tarragona. Bajo este objetivo, emerge un urbanismo acorde con la nueva funcionalidad de las ciudades, pero este no deriva de la SC en sí misma, puesto que esta es una de las múltiples formulaciones - quizá la más propagandística y futurista - de un urbanismo neoliberal que impone el valor de cambio por encima del valor de uso en nuestras calles.

Por eso, resulta necesario ubicar la SC en la posición que ocupa dentro del urbanismo neoliberal, entendiendo que este es «[...] parte integral de un amplio reescalamiento de funciones, actividades y relaciones que conlleva un considerable énfasis en el nexo entre producción y capital financiero a costa de cuestiones relativas a la reproducción social» (Smith, 2002: 255).

En su ideación, la SC es una defensa de la noción de la ciudad como máquina de crecimiento (Logan y Molotch, 1987) generadora de oportunidades de plusvalía y se presenta como un paso más de la transición de la ciudad keynesiana ${ }^{3}$ liberal a una ciudad neoliberal. La SC como última expresión del urbanismo neoliberal se cubre bajo el discurso que otrora ejecutara la ciudad keynesiana, pero se desarrollaría sin la aplicación de sus medidas. Publicita los atributos de la ciudad keynesiana en tanto que esta era «una mezcla de oficina de empleo y oficina de servicios sociales al servicio del capital nacional correspondiente» (Smith, 2002: 251), pero las evidencias empíricas en casos como el 22@ de Barcelona (Dot y Pallarés-Barberà, 2010) indican que la SC apuesta más por el negocio inmobiliario del coworking que por la vivienda protegida; más por la ciudad de oficinas que por la ciudad de oficinas de servicios sociales.

En este sentido, la SC aspira a redefinir la ciudad a partir de la realización de parques de alta tecnología (Gibson et alii, 1992; Hollands, 2008) y la integración de tecnologías ubicuas (Yigitcanlar y Lee, 2014). Es decir, la

3 La ciudad keynesiana en la que el Estado aseguraba grandes áreas de la reproducción social — desde la vivienda a los servicios sociales- representó la culminación de la relación definitiva entre escala urbana y reproducción social (Smith, 2002). 
retórica SC ha traspasado la noción de una tecnópolis aislada, orientándose a la expansión hacia el resto de la ciudad (Michelini et alii, 2010), con el fin de articularse como una fórmula estratégica para mejorar el posicionamiento de las ciudades involucradas en una competición global (Caragliu et alii, 2011). Realzar su posicionamiento significaría incrementar la atracción de flujos de capitales y de mano de obra cualificada mediante la producción de espacios tecnologizados.

A pesar de su voluntad de expansión, ejemplos como Kista en Estocolmo o el Here East londinense (Angelidou, 2015) muestran como estos polos tecnológicos siguen concentrándose espacialmente más que afectar generalizadamente al conjunto de la ciudad. Igual que sucede en edge cities como en Santa Fe, México (Pérez Negrete, 2009). Sin embargo, esto no significa, necesariamente, que su función de placebo urbano para la atracción no se encuentre en funcionamiento.

Conceptualmente, los expertos coinciden en atribuir diferentes ámbitos de actuación a la SC: la economía, la movilidad, la gobernabilidad, el medioambiente, la población y los modos de vida (Giffinger et alii, 2007; Hollands, 2008; Caragliu et alii, 2011). También presentan, de forma más o menos exacta, las siguientes características comunes para el concepto: el uso de tecnologías de la computación para convertir los componentes y las infraestructuras de la ciudad en más eficientes (Washburn et alii, 2010; Caragliu et alii, 2011).

Gran parte de la literatura vincula la SC con la conversión de la ciudad en un receptáculo de tecnologías. Definen el ámbito urbano como objetivo de intervenciones tecnológicas (Rabari y Storper, 2014) para convertir determinados fenómenos en previsibles (Glasmeier y Christopherson, 2015). Esto es, «la idea de que la tecnología nos salvará» (Vanolo, 2014: 892), un postulado que actúa bajo una lógica despolitizadora al suponer las problemáticas urbanas como categorías tecnológicas y no políticas (March y Ribera-Fumaz, 2014). 
La lógica smart identifica las ciudades como nuevas oportunidades para el sector privado en busca de nuevos mercados ${ }^{4}$. Especialmente para grandes empresas tecnológicas que juegan un papel destacado en el auge y popularidad del concepto smart (Hollands, 2008).

De este modo, las ciudades inteligentes se componen de start-ups integradas en clústeres tecnológicos, distritos tecnológicos (Komninos, 2006) y universidades que ahora orientan sus funciones hacia la economía de la información. Así, la SC supone la introducción de las ciudades posindustriales en la economía informacional mediante su transformación en espacios paradigmáticos para el negocio (Glasmeier y Christopherson, 2015) y para un capital que «[...] impone su propio trato para instalarse en la ciudad, moviéndose únicamente hacia donde recibirá un mejor trato. Este hecho es tan presente en la smart city como lo era en la ciudad industrial $^{5} »$ (Hollands, 2008: 314).

Las cualidades que la misma SC se atribuye - un giro hacia un urbanismo más sostenible ambientalmente, una gobernabilidad más participativa y unas ciudades más equitativas gracias a las nuevas tecnologíasse cuestionan bajo el que parece ser el principal objetivo de este concepto: facilitar la entrada de capital en la ciudad convirtiéndola en un entorno bussiness friendly. Esto significa la constitución de una ciudad más abierta al capital y la introducción de agentes privados en el desarrollo urbano que intensifican el «asalto neoliberal contra la administración pública» (Harvey, 2013: 132).

Resulta difícil comprender la SC como una opción efectiva para el beneficio de la mayoría de agentes urbanos mientras se oriente hacia valores neoliberales y sitúe la gobernabilidad urbana como un nuevo mercado (Buck y While, 2017), repleto de productos ideados por empresas que ven cómo incrementan sus beneficios, pero también su rol en el gobierno urbano. Los productos aplicados en la smartización de la ciudad permiten a las empresas vinculadas con el desarrollo smart introducirse en el gobierno de las ciudades mediante organismos público-privados, en detrimento de una gobernabilidad verdaderamente pública.

\footnotetext{
4 El mercado global SC se estimaba en 1,7 billones de dólares en el año 2014 (Poole, 2014; Hollands, 2014).

5 La traducción de las citas textuales consultadas en un idioma diferente al castellano es propia.
} 
La SC defiende que las tecnologías mejoran la capacidad de las sociedades liberales democráticas y los valores políticos centrados en el individuo. Hollands (2008) desconfía de esta perspectiva y afirma que la SC no es más que una etiqueta de marketing, un caballo de Troya para la inserción y dominación del sector privado en el ámbito urbano.

La ciudad inteligente es la expresión de un capitalismo «brutalmente neoliberalizador que ha venido intensificando su asalto a las cualidades de la vida cotidiana desde principios de la década de los noventa» (Harvey, 2013: 9). Parece ser una nueva manifestación de la ciudad neoliberal al convertir los componentes urbanos en objetos de negocio gracias a un fenómeno de mercantilización extendido por la aplicación de nuevas tecnologías. Esto significa la consolidación de una urbanización por desposesión (Harvey, 2003) que presenta, ambiguamente, una retórica embellecida por el derecho a la ciudad.

Este modo de neoliberalización también impone una nueva relación entre gobierno y saber que despolitiza la esfera pública mediante procesos institucionalizados de gobernanza desideologizados basados en criterios científicos y técnicos (Janoschka e Hidalgo, 2014). Por eso, la gobernabilidad en la SC se orienta hacia la mercantilización. Las empresas relacionadas con el negocio tecnológico ven en este contexto un nicho donde aplicar - y vender - los productos resultantes de cuarenta años de desarrollo tecnológico (Glasmeier y Christopherson, 2015). La apertura del gobierno de las ciudades al mercado se realiza con el beneplácito de una Administración concentrada en el objetivo de situarse en los rankings mundiales, conseguir inversión y crecimiento (Glasmeier y Christopherson, 2015).

Aunque la SC se publicite como un modo de gobernanza transparente, basado en la participación digital y la inclusión de una multiplicidad de actores, sus intervenciones - a menudo elitistas y opacas - presentan un individualismo latente (Rabari y Storper, 2014), ubicando el ideal de smart citizen en un sujeto individualizado de clase media. Mientras que su ideal de gobernanza y de servicios urbanos se reserva a tecnócratas que, «atados a un único escenario, se convierten en "estadistas" del crecimien- 
to antes que en defensores de un tipo determinado de crecimiento o de distribución interna de sus rentas» (Logan y Molotch, 1987: 180).

Dado que el modelo de decisiones smart amplifica la presencia de los sectores privados en la gobernanza de las ciudades, hay que preguntarse si la SC, como forma de crecimiento urbano vinculado al sector privado (Hollands, 2008), se encuentra más preocupada en la atracción de inversiones y en la generación de nuevos negocios en la ciudad que en la calidad de vida de sus habitantes.

\section{La génesis bicéfala de la Tarragona Mediterranean Smart city}

Para comprender el desarrollo y funcionamiento del paradigma SC en Tarragona es necesario analizar el origen del desarrollo de sus iniciativas locales. Sin embargo, debemos comprenderlas como expresiones locales de intensas campañas —en un marco europeo- para la promoción de procesos de regeneración urbana. Unas estrategias en crisis derivadas del debilitamiento del poder de la organización de la reproducción social en la definición de lo urbano (Smith, 2002).

La implementación de programas SC en Tarragona se ha realizado en el marco de la celebración de los Juegos del Mediterráneo (JJ. MM.) de 2017 - aplazados a 2018- y al Pla Tarragona 2022. En el contexto de estas dos acciones, la estrategia SC en Tarragona se ha erguido como uno de los principales discursos del Ayuntamiento sobre la transformación sociourbana que tiene que afrontar la ciudad. El alcalde de Tarragona, Josep Félix Ballesteros, evidenciaba este hecho en uno de sus discursos: «Es ahora cuando la ciudad empieza a concretar las acciones del Tarragona Smart Mediterranean City y del Pla Tarragona 2022. [...] viviremos el inicio de proyectos muy destacados para el futuro de la ciudad» (Josep Félix Ballesteros, 2013: 1) 


\subsection{Los XVIII Juegos Mediterráneos}

En primer lugar, centrémonos en los JJ. MM., una competición deportiva multidisciplinar disputada cada cuatro años con la participación de los Estados adyacentes al Mediterráneo. Para la ciudad, han significado la ejecución de un macroevento, sujeto a las dimensiones de Tarragona, y deberían cumplir la voluntad de exhibición internacional. Han sido aprovechados por los dirigentes políticos para presentar un supuesto renewal urbano en tanto que albergar este evento implica cambios en las dimensiones físicas y conceptuales de la ciudad.

Pero también significa la creación de una nueva imagen atractiva de la ciudad (Monus, 2015). En este caso, mediante los JJ. MM. se quiere introducir la visión de una Tarragona moderna, un imaginario habilitado por la última nomenclatura vinculada al progreso y al crecimiento económico en las ciudades: la smart city. Siguiendo, así, un modelo popularizado por la Barcelona olímpica, pues la estrategia del poder local respecto a los JJ. MM. no es otra que reproducir la estrategia de la ciudad vecina. Barcelona, desde su eclosión como ciudad global modélica, debido, justamente, a la celebración de los Juegos, ha acentuado la emulación de sus estrategias, sobre todo en ciudades cercanas. Lógicamente, este método de transformación urbana tiene múltiples claroscuros, como muestran, entre otros, Capel (2005) o Delgado (2007).

Mediante el nuevo imperativo informacional adquirido por el consistorio local se ha incorporado a la necesidad de reforma y «mejora» urbanística la construcción de aplicaciones y de infraestructuras digitales en la ciudad. A diferencia de las construcciones físicas derivadas y justificadas por la celebración en sí misma de los JJ. MM., la tecnologización de la ciudad no se legitima únicamente a partir de este evento. Más bien es planteada como una necesidad inherente de la ciudad, la principal baza de la narrativa legitimadora de la SC en Tarragona.

La SC es presentada como uno de los principales legados de este evento a partir de afirmaciones del alcalde, tan rotundas como improbables, como la siguiente: "Queremos convertir el Camp de Tarragona en el Smart Valley del sur de Catalunya» (en Sans, 2014: s. p.). 
Las características de los JJ. MM como evento deportivo que enaltece los valores vinculados al deporte, como la salud y el afán de superación (Monus, 2015), se suman a la retórica mesiánica de la tecnología como motor de todo tipo de beneficios: desde económicos hasta sociourbanos. Que las estrategias smart actúen bajo la etiqueta de «mediterraneidad» no es casualidad, sino que expresa la vinculación directa entre los JJ. MM. y la estrategia SC de la propaganda política local ${ }^{6}$.

En el caso de Tarragona, la mayoría de políticas vinculadas al concepto SC se encuentran enlazadas con el marketing que la ciudad desarrolla para los JJ. MM. (Gil y Navarro, 2013). A los JJ. MM. y al estatus que a partir de estos se quiere conferir a la ciudad, hay que añadir el urbanismo smart como medida para incorporar una nueva etiqueta que presente una visión de prosperidad a la ciudad.

El legado de los JJ. MM. prometido es abundante y prolífico según un consistorio que entiende el evento como «la gran oportunidad para definir y fijar el legado de Tarragona [...], tiene que personificar el espíritu de transformación de la ciudad» (Josep Félix Ballesteros, 2013: 6).

Los impulsores afirman - sin aportar ejemplos descriptivos ${ }^{7}$ - que, pese al carácter principalmente económico del legado de los JJ. MM., su herencia será un fenómeno multidimensional basado en el incremento de las infraestructuras y la mejora ambiental y social. Por el momento, la principal funcionalidad de estos discursos se alinea con la legitimación de la política local promotora del macroevento y el mismo desarrollo de los JJ. MM.

Según el Plan Estratégico del Legado de los Juegos Mediterráneos Tarragona 2017, uno de los principales objetivos a partir de los Juegos es mejorar el capital humano, y su ocupabilidad en sectores de futuro como el tecnológico. Unos argumentos acordes con las directrices planteadas por la SC en su alineamiento con la economía de la información.

Sin embargo, las estrategias vinculadas al desarrollo de la economía de la información se presentan escasas. Solo la propuesta Camp Tgn Up

6 Ante la inminente celebración de los JJ MM., la FTSMC difundía este vídeo: <https://www.youtube. com/watch?v=V7hokgW95GA>.

7 Entre los materiales se encuentra el siguiente vídeo, realizado por la FTSMC: <https://www.youtube.com/watch?v=-jorp-3-yio>. 
- una aceleradora que pretende impulsar diez start-ups — ha sido iniciada hasta el momento, siete años después de la adjudicación de los JJ. MM.

La escasez de proyectos para cumplir con las directrices del plan supone que los Juegos y la SC se subsuman en estrategias de propaganda y de legitimación bidireccionales más que en propuestas concretas. Un hecho basado en la venta de una aparente informatización e informacionalización de la ciudad que deja en segundo plano la intervención real para la mejora de las condiciones de la ciudadanía.

Queda por constatar si la celebración de los Juegos repercutirá en la ciudad y sus habitantes a largo plazo, aparte de generar un determinado número de empleos esporádicos durante su realización, ampliar el parque de infraestructuras deportivas para el fomento del turismo deportivo y dejar, como herencia, el confuso e incipiente urbanismo smart.

Según el informe del Centro de Estudios Olímpicos de la UAB (CEO$\mathrm{UAB}, 2015$ ), encargado por el Servicio de Ocupación de Cataluña y el Ayuntamiento local, los JJ. MM. debían suponer la creación de 300 empleos directos derivados de la planificación y ejecución de los mismos y generar una ocupación indirecta, antes y durante los JJ. MM., estimada en 3.000 empleos provenientes de empresas de servicios (CEO-UAB, 2015).

Pese a que el empleo ha sido usado como artefacto ideológico en la legitimación de los Juegos, siendo un elemento clásico en la naturalización de la ciudad como máquina de crecimiento local, el carácter eventual de la ocupabilidad generada se suma al hecho de que «el crecimiento local no genera empleos, solo los distribuye» (Logan y Molotch, 1987: 196). Sin embargo, la escasez de datos proveídos por los organizadores del evento no permite contrastar, a la publicación de este artículo, si las cifras estimadas han sido adquiridas ${ }^{8}$.

Para la postura justificadora del consistorio, los múltiples beneficios sociales y urbanísticos del evento quedan ampliamente contrastados en las líneas de actuación del Plan Estratégico, aunque resulta difícil contrastar los beneficios de sus predicciones con la información que ofrece. Una transparencia impropia de los rigores smart.

8 Este hecho ha supuesto que determinados grupos políticos amenacen con recurrir a la Comisión de Garantía del Derecho de Acceso a la Información Pública mediante un contencioso administrativo. 
En este sentido, las decisiones estratégicas vinculadas a los Juegos, así como sus presupuestos, desatienden los programas sociales para invertir en proyectos donde el beneficio común no es evidente.

Un ejemplo es el polideportivo Sant Jordi, este complejo situado en el centro de la ciudad ha sido reconvertido en un moderno gimnasio gestionado por el sector privado. Los costes de este equipamiento, 12 millones de euros, han sido aportados por la iniciativa privada mediante un acuerdo con la URV (Ajuntament de Tarragona, 2017b).

Aunque estas instalaciones ofrezcan descuentos a las personas vinculadas a la Universitat Rovira i Virgili (URV), su principal objetivo no es el servicio público. Bajo la hipotética generación de emplazamientos deportivos para los Juegos que debería incrementar el número de espacios para la ciudadanía, se esconde la privatización de espacios emblemáticos.

En definitiva, los JJ. MM. y la transformación smart de la ciudad deben contemplarse como dos de las principales políticas de la ciudad que, como tales, se retroalimentan, y son publicitadas, sin garantía de ello, como los «grandes motores que tienen que mover el futuro inmediato de nuestra ciudad para llevarla a un nuevo nivel, a un nuevo paradigma de ciudad» (Josep Félix Ballesteros, 2014: s. p.).

\subsection{Pla Tarragona 2022}

En segundo lugar, el otro eje político que da sentido a la presencia SC en la ciudad es el Pla Tarragona 2022, la principal hoja de ruta del desarrollo urbano de la ciudad. Este realza la supuesta necesidad de la ciudad para ser competitiva y referente en la sociedad del conocimiento.

Las políticas municipales amparan la lógica SC e informacional con base en este plan. Para los promotores de la iniciativa SC en Tarragona, el proyecto resume las directrices para la conversión smart: «El plan estratégico Tarragona 2022 resumió en siete ejes estratégicos fundamentales las prioridades [...] que configuran la agenda transformadora de Tarragona como una smart city» (Fundació Tarragona Smart Mediterranean City, 2016: 6).

El documento incluye en su diagnóstico la necesidad de desarrollar programas que favorezcan la conversión de cada barrio en un centro es- 
pecífico, solventando las problemáticas existentes mediante lógicas temáticas, creando la ciudad deportiva en Poniente, la ciudad de la música en Levante y el futuro e hipotético Smart District en Les Gavarres.

El proyecto también detecta como necesidad la conversión de Tarragona en un polo de innovación competitivo para integrarse en la economía del conocimiento. El principal recurso para cumplir este objetivo es el uso de nuevas tecnologías y la captación de empresas dedicadas a la innovación.

En otras palabras, el Ayuntamiento pone de manifiesto la necesidad de convertir Tarragona en una ciudad de la ciencia ${ }^{9}$ que le permita integrarse en nuevos mercados emergentes vinculados a la tecnología, creando instituciones informacionales y aprovechando las existentes, como la universidad. Pero el documento no discrimina el hecho de si esto supone la apertura, también, de la ciudad como mercado para las empresas tecnológicas, una de las consecuencias de la smartización de la ciudad.

Para la consecución de sus objetivos, el Pla defiende la necesidad de aplicar nuevas tecnologías en la gobernabilidad de la ciudad, generando canales de participación y haciendo más eficiente la Administración. Pero las propuestas que hasta el momento se han desarrollado en esta dirección, y que significarían un impacto directo en el bienestar de la ciudadanía, son más bien escasas.

Uno de los pocos ejemplos es la aplicación móvil Epp!. Tiene el objetivo de que los y las ciudadanas puedan avisar sobre incidencias relativas a la vía pública. La falta de otras iniciativas supone que la materialización smart en la gobernabilidad tenga solo un carácter técnico para los habitantes, ahora reconvertidos en detectores del mal estado del pavimentado público o del alumbrado.

En todo caso, para el Ayuntamiento las directrices del documento combinan la necesidad de integrar las tecnologías ubicuas con la orientación hacia la economía de la información en el desarrollo urbano, incluyendo estrategias para la sostenibilidad en la ciudad con la promoción del transporte público, la creación de entornos urbanos saludables, bajo

9 De hecho, Tarragona se postuló para la distinción de Ciudad de la Ciencia y la Innovación en 2016 mediante un informe de la FTSMC. 
un planteamiento higienista, y la sensibilización de la ciudadanía en relación al impacto medioambiental (Ajuntament de Tarragona, 2011).

Aunque la política local defienda que Tarragona tiene los recursos necesarios para convertirse en un polo de la economía de la información, la realidad es que los principales motores económicos, como vimos, son el portuario, el petroquímico y el turismo. Esto se hace más evidente cuando tenemos en cuenta los datos relativos a los trabajadores vinculados al sector tecnológico. El total de trabajadores en sectores tecnológicos se divide en 186 profesionales de las tecnologías de la información y 836 técnicos de las tecnologías de la información y las comunicaciones (TIC) (SEPE, 2017). Entre los primeros, un $38,71 \%$ ostenta un contrato indefinido, frente a una temporalidad que asciende al 61,29\% (SEPE, 2017). Entre los técnicos de las TIC este dato se incrementa, ascendiendo a una temporalidad contractual del $77,27 \%$ frente a un número de indefinidos del $22,73 \%$ del total (SEPE, 2017).

La escasa presencia de un número mayoritario de profesionales y técnicos de las TIC, así como su alta temporalidad, indica la falta de una masa crítica de trabajadores desde la cual instituir un polo tecnológico. En cambio, observamos que existe un total de trabajadores del «70,39\% en el sector servicios, principalmente en hostelería» (SEPE, 2017: 12).

Además, pese a no ostentar el prestigio de la economía de la información, las iniciativas smart de la ciudad se articulan con los agentes económicos presentes -industria química, intereses turistificadores y el puerto-, constituyéndose como los principales patrones del organismo privado creado en el año 2013 por el Ayuntamiento con el objetivo de concentrar e impulsar intervenciones SC: la Fundació Tarragona Smart Mediterranean City (FTSMC).

Se trata de un organismo dependiente del Ayuntamiento ${ }^{10}$ y que rinde cuentas a sus cuatro patrones: el consistorio, la URV y las empresas Repsol y Sorea. La presencia de estas empresas en la FTSMC tiene que considerarse como algo más que una simple acción filantrópica que se materializa en inversiones e intervenciones positivas para la ciudad. Me-

10 Concretamente: Àrea de Serveis Centrals, Economia i Hisenda, Servei de Patrimoni del Ajuntament de Tarragona. 
diante la fundación, los principales agentes privados interesados en la implementación de programas SC, Repsol y Sorea, y consecuentemente con intereses en las políticas urbanas en Tarragona, se incorporan como interventores activos de la agenda política urbana, con las carencias democráticas que este hecho conlleva.

En este sentido, Vanolo (2014) plantea el funcionamiento de una técnica disciplinaria derivada de los fondos europeos para el financiamiento de iniciativas smart, destinados a unas ciudades que para acceder a estos se encuentran obligadas a abdicar delante de los imperativos SC. En Tarragona, aunque en una escala diferente, se debe tener en cuenta que la intervención privada puede condicionar las políticas urbanas locales a los intereses empresariales. Así, a nivel local se reproduce la misma situación estatal: las intervenciones del Estado se ven reducidas, en parte, a la función de encontrar más modos para promover un clima económico favorable (Harvey, 2001).

En consecuencia, esto implica unas ciudades disciplinadas, preparadas para ser ocupadas por técnicas tecnopolíticas diseñadas para naturalizar y justificar las nuevas formas de circulación del capital dentro de los sistemas urbanos (Vanolo, 2014). Es decir, unas ciudades que introducen valores neoliberales en su entramado urbano en un contexto donde los entornos business friendly pueden resultar menos amigables para los y ciudadanos.

Si bien es cierto que la FTSMC opera con cierta independencia, reconoce la necesidad de combinar inversiones públicas y privadas que deben «permitir incorporar el sector privado en la regeneración de la ciudad» (FTSMC, 2013: 4). Para la institución, la introducción de agentes privados en su estructura es considerada como una solución para facilitar la gestión.

Por último, hay que considerar el gran peso que la fundación da a la comunicación. La publicitación de lo smart y la hipervisibilización de sus iniciativas parece inclinarse más por el marketing que por la intervención; más por la retórica que por la transformación. Especialmente aquellas que se vinculan con el incremento del papel de la ciudadanía en la gobernabilidad de la ciudad, de presencia casi nula en los diferentes frentes abiertos por la política smart. 


\section{Iniciativas de intervención urbana smart city en Tarragona}

Desde el inicio del funcionamiento de la FTSMC se han llevado a cabo variopintas iniciativas de corte smart en la ciudad. La fundación desarrolla proyectos en ámbitos como la sostenibilidad ambiental, el patrimonio y la economía, vinculándose con otras instituciones locales para llevarlas a cabo.

Una muestra es el programa «Hélix», un proyecto de economía colaborativa para la generación de nuevas herramientas para personas con movilidad diversa a partir del reciclaje de plástico con una impresora 3D. Otro caso es el proyecto «Smart Cub», donde el Institut Pere Martell, junto con la FTSMC y la Autoritat Portuària, llevó a cabo la reconversión de un contenedor de mercaderías portuarias en desuso en un espacio de divulgación científica.

La fundación también se vincula con el Institut Pere Martell con otras iniciativas. Por ejemplo, el proyecto «ELECO», basado en la realización de un coche eléctrico de competición por parte de alumnos del centro. Además, lleva a cabo otros proyectos en centros educativos, como el programa «Smart Tarragona Energy Efficiency Project in Schools»: una actividad divulgativa en las escuelas para informar sobre prácticas de ahorro energético entre los alumnos.

Puesto que la introducción de iniciativas SC en Tarragona responde a las voluntades de internacionalización de la ciudad, se han desarrollado proyectos SC a favor del turismo y del patrimonio histórico (Gil y Navarro, 2013). La vinculación de la FTSMC con el Servei de Patrimoni del Ayuntamiento, sumado al hecho de que la concejala de Festes, Cultura i Patrimoni Històric es también la secretaria general de la FTSMC, conlleva la prevalencia de proyectos vinculados al smart heritage en la fundación, como por ejemplo «Cívic Tàrraco y Reliving Tàrraco». La entidad parece haber perdido el interés en la economía de la información para decantarse hacia uno de los motores económicos de la ciudad: el turismo.

A nivel de infraestructuras y medioambiente, los principales proyectos smart de la fundación se concentran en a) el aislamiento térmico en diferentes escuelas con un sistema suministrado por la empresa BASF para medir el ahorro de energía resultante; $b$ ) un análisis del impacto del 
transporte público; c) un proyecto piloto sobre el uso de biocombustibles producidos por algas marinas, desarrollado por Repsol; d) la introducción de un sistema de medición inteligente del agua en barrios y piscinas públicas impulsado por AGBAR y EMATSA; e) el control de la calidad de las aguas en playas de Tarragona con resultados accesibles para smartphones; $y$, finalmente, $f$ ) la sensorización de los accesos a la Part Alta para obtener información precisa sobre el número y el tipo de vehículos que acceden al barrio para ajustar las políticas de movilidad correspondientes (Gil y Navarro, 2013).

A pesar de estas iniciativas, es difícil encontrar evidencias de la hipotética transformación smart de la ciudad cuando se pasea por la misma. Una de las pocas que pueden encontrarse por sus calles (Rambla Nova y cerca de la plaza de les Corts Catalanes) son los dispositivos de carga de smartphones. Este proyecto, impulsado por EMATSA, «funciona a partir de una picoturbina que aprovecha la regulación de presiones que se hacen en la red urbana de agua potable» (EMATSA, 2015 $5^{11}$. El sistema, que incorpora tres soportes de carga y se adapta a las necesidades de personas con movilidad diversa, no se encuentra operativo actualmente debido a la desaparición de parte del cableado.

Las diferentes intervenciones no presentan un nexo común más allá de situarse bajo el amplio y confuso paraguas smart, o de intentar dar sentido a las directrices que los dirigentes políticos han determinado bajo estas transformaciones para modernizar y hacer más eficiente, a la vez que sostenible, la ciudad.

El proyecto que propone una modificación más profunda, y a gran escala, es el Ikea Smart Housing (Pla Parcial 10-IKEA). Se trata de una propuesta proyectada en 2013 para la construcción de un barrio inteligente cerca del centro comercial de Les Gavarres, donde tendría que ubicarse una sucursal de la empresa IKEA. Según el consistorio, se tratará de un barrio moderno, sostenible y con visión de futuro (Ajuntament de Tarragona, 2013).

11 Se puede consultar el proyecto en: <https://www.ematsa.cat/ematsa-implanta-carregadors-per-a-dispositius-mobils-amb-energia-renovable-en-diferents-punts-de-la-ciutat/>. 
Vendido con la etiqueta Mediterranean Smart District (MSD), pese a ser sede hipotética de una empresa escandinava, proyecta la construcción de 1.200 viviendas de las cuales más de 300 serán de protección pública (Gosálbez, 2017). La ubicación proyectada para el MSD es en el desaparecido barrio de la Esperanza, un emplazamiento precario y de extrema pobreza. El inicio de la construcción se ha pospuesto hasta fechas similares a la celebración de los Juegos. Si el barrio terminase construyéndose, se trataría de una edge city boomer (Garreau, 1991), caracterizada por su construcción próxima a malls, en este caso: Les Gavarres.

Esta iniciativa parece ser la materialización y la concentración espacial del urbanismo smart defendido por el consistorio. Nuevamente, mediante la lógica público-privada, se instituye un megaproyecto que parece responder más a lógicas verticales que a la supuesta gobernabilidad horizontal de la SC. Pese a que los responsables del proyecto afirman que el $25 \%$ de los inmuebles se destinarán a protección social, las tendencias elitizadoras que acompañan la generación de barrios modernos tecnologizados — como en Barcelona (Dot y Pallarés-Barberà, 2010), Londres (Beanland, 2012) o en la ciudad india de Dholera (Datta, 2015) — dan una noción del público de clase media al que se orientarían.

El caso de desarrollo urbano de IKEA en Tarragona no es único. La empresa de muebles también lleva a cabo iniciativas similares en Hamburgo (Gutzmer, 2015) y en Londres (Hollands, 2014), donde adquirió 5.219 metros cuadrados en el desindustrializado Strand East para la edificación de un barrio con características similares a la propuesta de Tarragona.

El objetivo de estas iniciativas, según IKEA (Andrew Cobden en Beanland, 2012) es trabajar conjuntamente con las autoridades para transformar determinados distritos en emplazamientos modernos y sostenibles. Pero las principales problemáticas de este hecho residen en las capacidades de control que adquieren los actores privados en un espacio que pierde la categoría de público al conectarse con el control corporativo (Gutzmer, 2015). El proyecto londinense de IKEA evidencia que la privatización de terrenos públicos por parte de empresas privadas es una tendencia al alza en Inglaterra (Minton, 2012), un hecho que mediante la lógica SC puede ir extendiéndose a Tarragona. 
La razón del cambio de orientación del negocio del mueble al del inmueble de IKEA puede ser debida a una estrategia para introducirse en inversiones relativamente más estables que la dependencia de un único sector (Gutzmer, 2015). Además, la incorporación de equipamientos y servicios urbanos requeridos por la economía de la información aseguraría a IKEA una posición predominante en el mercado SC.

Por último, la siguiente ilustración localiza las principales iniciativas SC presentadas ${ }^{12}$.

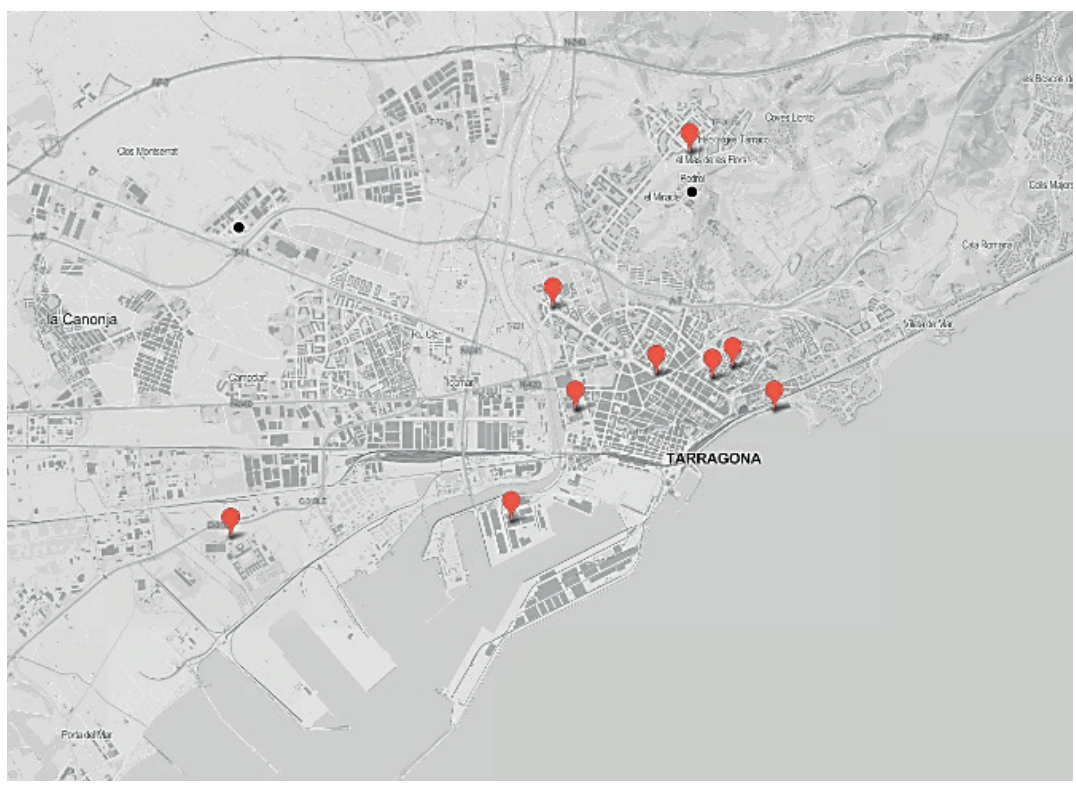

Ilustración 1. Localización de las iniciativas SC analizadas. Elaboración propia.

12 Los círculos corresponden a la sede de la FTMSC (derecha) y al hipotético Smart District (izquierda), mientras que las señalizaciones restantes indican las principales iniciativas SC presentadas. 


\section{De la producción de tabaco a la improductividad de la ecoestética smart: la Tabacalera como emblema de la Tarragona inteligente}

En el año 2012, el Ayuntamiento de Tarragona iniciaba las obras para construir un jardín vertical en la antigua fábrica de la Tabacalera - reconfigurada como Smart Parc Tabacalera- la cual tenía que convertirse en el emblema que representara la smart city de Tarragona.

Un gran número de tecnópolis y emplazamientos de alta tecnología han surgido de la reconversión de antiguos espacios industriales (Castells y Hall, 1994). A menudo, estas nuevas tecnópolis o emplazamientos tecnologizados suponen la continuación de la dominación metropolitana, pero en el caso de la Tabacalera su emplazamiento se sitúa dentro de la propia ciudad.

A diferenciadel 22@ barcelonés, que se instituye mediante la reindustrialización tecnológica del desindustrializado Poblenou, Tarragona aún sustenta fuertes dependencias y actividad en el sector industrial presente en la ciudad. Sin embargo, parece quererse emular el modelo de la Ciudad Condal en la reutilización de espacios industriales emblemáticos. La Tabacalera sostiene fuertes similitudes con la refuncionalización de antiguos recintos industriales de la capital catalana, como Ca l'Alier, reconvertido en un centro para la compartición de bigdata y de debate SC, o el campus de la Universidad Pompeu Fabra en Ca l'Aranyó.

La inauguración de este complejo industrial data del año 1931. Se trata de un edificio industrial con 43.931,10 $\mathrm{m}^{2}$ de superficie útil, reservado a la producción de cigarrillos y derivados del tabaco. Durante los años sesenta, la fábrica fue el centro productor de Tabacalera S.A., llegando a producir 30 millones de paquetes de tabaco.

En la Tabacalera se generó una vida social vinculada al sindicalismo, pero también al asociacionismo, celebrando diferentes actos organizados por los trabajadores y otros fomentados por las autoridades directivas.

La importancia del edificio, sumada a sus características arquitectónicas - estructura racionalista, ornamentación clasicista de las fachadas, amplios pabellones, patios y jardines-, ha conllevado el reconocimiento del emplazamiento como bien cultural de interés local. 
Los trámites para la adquisición pública de la fábrica se iniciaron en el año 2003, mediante la negociación entre Altadis, la empresa propietaria de la fábrica, y el entonces Gobierno municipal de Convergència i Unió (CiU). El 23 de marzo de 2007 abandonaron la fábrica los últimos 33 trabajadores que quedaban en activo (Aymi, 2007), poniendo fin a su actividad industrial. Las negociaciones se materializaron en el año 2005, concluyendo con un acuerdo para la adquisición por parte del Ayuntamiento de las instalaciones de la Tabacalera a la multinacional Altadis. Una operación calificada como polémica por determinados activistas de la plataforma Oppida en tanto que la fábrica es cedida a cambio de unos terrenos que permitirían la edificación de múltiples viviendas.

La operación se formaliza, finalmente, en 2008, bajo el Gobierno socialista del actual alcalde. Este hecho provoca la competencia por atribuirse el mérito de adquirir el espacio, CiU reprocha al alcalde actual la falta de reconocimiento del Gobierno anterior, iniciador de las negociaciones (Ponsatí, 2008).

Más allá de disputas políticas, supuso la incorporación de casi 60.000 metros cuadrados al parque público. Según los argumentos políticos de la época, la zona tenía que convertirse en un nuevo polo de crecimiento situado en la Part Baixa de la ciudad, concentrando diferentes instituciones y equipamientos que se localizaban en la Part Alta de la ciudad, o que no podían ubicarse ahí por cuestiones espaciales.

Las promesas del consistorio de concentrar una multiplicidad de equipamientos en el emplazamiento aún no se han visto cumplidas. Un número escaso de actividades ocupa el edificio - la sala de conciertos Capsa de Música, el Arxiu y Tarragona Impulsa-en comparación con el gran espacio vacante y la actividad prometida.

Este último organismo, el antiguo servicio de ocupación municipal, se trasladó en 2012 al edificio. La institución ha habilitado en el Magatzem 1 de la Tabacalera un espacio de formación, una bolsa de trabajo, un espacio reservado a empresas y una zona de coworking destinada al alquiler de despachos para start-ups (Ajuntament de Tarragona, 2012).

De hecho, el Mi, a partir de Tarragona Impulsa y del consistorio, es la sede del programa «Open Future» de la empresa Telefónica en Tarra- 
gona. Se trata de una convocatoria para impulsar start-ups tecnológicas, accediendo las seleccionadas a seis meses de mentoría profesional, formación y encuentros con inversores.

En contraposición al espacio polivalente proyectado, el Ayuntamiento inició un conjunto de obras paisajísticas en el complejo bajo el nombre de Smart Parc Tabacalera. La intervención supuso la conversión de una de las fachadas, orientada a la calle Vidal i Barraquer, en un jardín vertical compuesto por plantas autóctonas y un sistema de riego publicitado como smart.

De este modo, el 23 de mayo de 2012 se inauguraba el jardín vertical más grande de Europa coronado por una pantalla de 13,44 por 7,68 metros con la función de retransmitir informaciones actualizadas y grandes eventos.

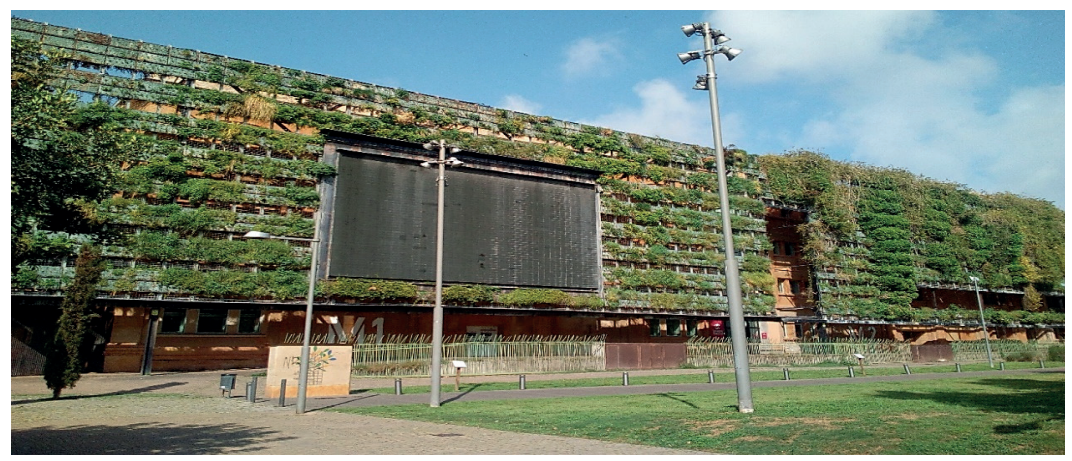

Ilustración 2. La Tabacalera, 2017.

Las principales denuncias de la plataforma Oppida, opuesta al proyecto desarrollado por el Ayuntamiento en la Tabacalera, se vinculan con la gestión de los equipamientos públicos por parte del consistorio, considerada partidista y electoralista, así como con la falta de espacios gestionados por colectivos y asociaciones de la ciudad. La plataforma considera que el edificio está sometido a un proceso continuo de degradación y se inspiran en centros de otras ciudades en funcionamiento (Can Batlló en Barcelona o la Tabacalera de Madrid) para reivindicar el derecho al acceso a los equipamientos públicos (Fàbregas, 2018).

Sus propuestas se basan en el establecimiento de un espacio común para las diferentes entidades y asociaciones de la ciudad que actualmente 
no tienen espacios ofrecidos por el consistorio. Oppida apela a las instituciones para garantizar el acceso a estos espacios y recrimina su falta de apoyo. Este espacio común, según sus propuestas, se ubicaría en el Magatzem 6 de la Tabacalera, empleando un 9\% del total construido (Gebellí, 2017).

La voluntad por instalarse en el edificio se debe, también, a razones simbólicas. Los trabajadores de la fábrica habían generado un tejido social muy importante y, según la plataforma, el edificio concentra una herencia de lucha y reivindicación que vuelve emblemática su instalación.

La herencia del asociacionismo y de las movilizaciones sindicales ha llegado hasta la actualidad a partir de la Associació d'Amics de la Tabacalera y Dones de Tabacalera, dos asociaciones que pretenden recuperar la memoria histórica y el patrimonio material y cultural inmaterial vinculado a la fábrica (Gebellí, 2017). Así, Oppida sostiene que el simbolismo de la Tabacalera reside en el significado que tiene el complejo en su constitución: «Sería muy simbólico que lo que en su momento fue la casa de la revolución industrial se convierta en la casa de la revolución cultural» (Gebellí, 2017: s. p.).

Entre las diferentes acciones de Oppida, destacan los actos convocados por la protesta de los diez años de inactividad de la Tabacalera. Estas protestas derivan del hecho que, a principios de 2017, la plataforma diseñó una propuesta de centro sociocultural autogestionado en el Magatzem 6. Aunque en principio el Ayuntamiento mostró cierta predisposición, finalmente se les negó el proyecto (Fàbregas, 2018).

La negativa del Ayuntamiento desembocó en diversas manifestaciones y en una ocupación simbólica con el fin de denunciar el mal estado del espacio a partir de acciones festivas (Fàbregas, 2018). Concretamente, el 3 de marzo de 2017 se llevó a cabo el «entierro de la cultura», una performance de corte irónico para evidenciar la problemática vinculada al complejo industrial. El acto, iniciado en Imperial Tarraco, tuvo su desenlace en la Tabacalera, donde se simuló el entierro de un ataúd delante del Magatzem 6. 


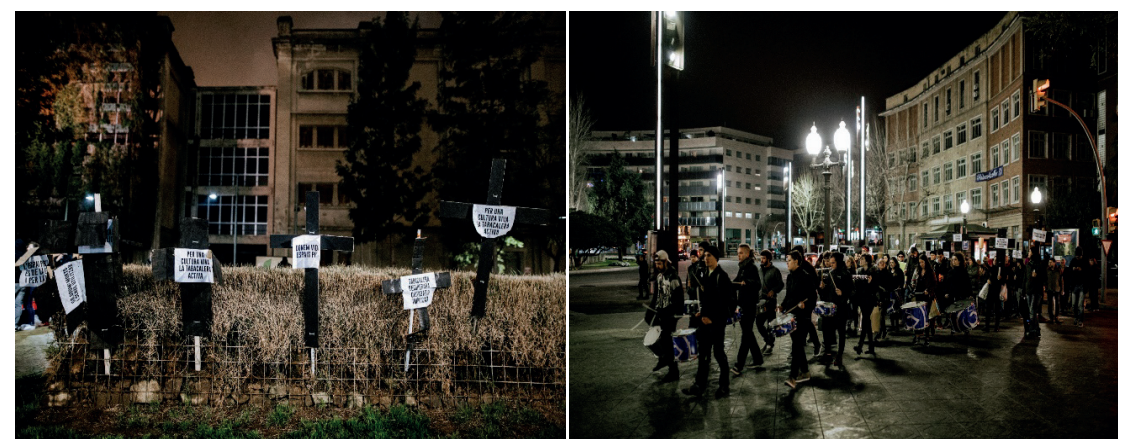

Ilustración 3. Entierro de la cultura. Autor: Albert Rué.

Las jornadas de reivindicación continuaron el día 11 a partir de una actividad vinculada. a la cultura urbana en la Tabacalera, realizando talleres de hip-hop, de grafiti, de pancartas y de funky. Además, el día 18 se organizó un debate sobre el modelo de espacio público y una paella popular, terminando la jornada el 25 de marzo con una manifestación.

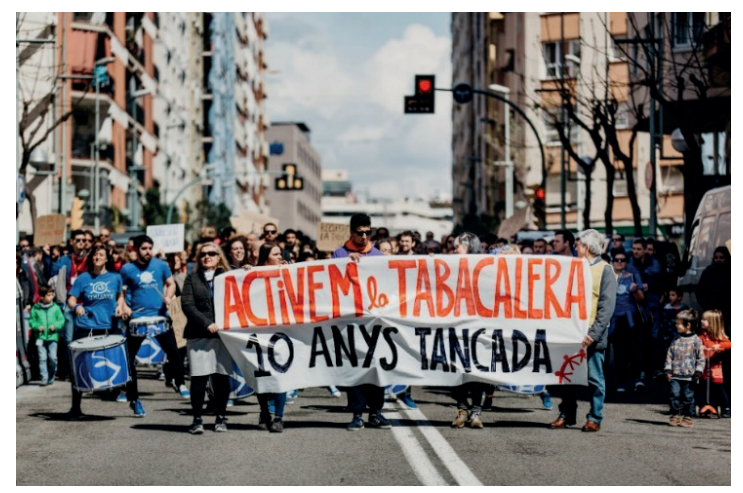

Ilustración 4. Manifestación de Oppida. Autor: Albert Rué.

Ante las protestas populares y la insatisfacción ciudadana evidenciada por la plataforma Oppida, el consistorio publicó en el año 2017 las bases técnicas que regirán el concurso (abierto en agosto de 2017) para el desarrollo funcional y arquitectónico de la Tabacalera. En este documento se reconoce que la ocupación actual es de solo un 16,2\% del edificio, «el resto de edificios se encuentran actualmente sin uso específico» (Ayuntamiento de Tarragona, 2017: 6). 
Según el Pla Funcional, la empresa que termine desarrollándolo debe incluir en los espacios del edificio los actuales equipamientos y un centro de creación y divulgación artística, entidades del mundo patrimonial, salas de exposiciones y, entre otros, espacios de autogestión vinculados a la cultura y al arte (Ayuntamiento de Tarragona, 2017).

Según la concejala de Patrimonio del Ayuntamiento (en Filella, 2017: s. p.), a partir del plan, «la Tabacalera debe ser el catalizador de la interpretación de la cultura clásica, del presente y del futuro». Queda por constatar si la elocuencia del plan acaba traduciéndose en la reactivación de la Tabacalera, o si la experiencia de una década de inactividad vuelve a imponerse.

Aunque el espacio termine convirtiéndose en un «centro dinamizador de la economía de la sociedad tarraconense a través de la cultura y de la emprendeduría» (Floria en Fàbregas, 2018: s. p.), su planteamiento economicista en el uso del espacio y de la comprensión de las actividades culturales no dará respuesta a las reivindicaciones vecinales.

Tampoco parece factible una activación a corto plazo de los espacios de la Tabacalera en tanto que una vez sea definido el Plan Funcional será necesario otro concurso público para determinar la empresa que lo realizará. En este sentido, el documento actual es un plan de planes que en sí mismo no supone la reactivación del espacio.

La reacción política concentrada en el Plan Funcional no ha venido acompañada por la rehabilitación y ocupación del espacio, aunque las evidencias presentadas por Oppida parecen haber obligado al Ayuntamiento a desarrollar una propuesta. Este último justifica su anterior inacción en las inestabilidades del contexto político, aunque el plan se generó en un año políticamente convulso como 2017 (Fàbregas, 2018). 


\section{Consideraciones finales: ¿todas las ciudades serán smart o no serán ${ }^{13}$ ?}

El estado actual del desarrollo de las iniciativas SC manifiesta que Tarragona no es una ciudad inteligente y que su construcción se encuentra en un estado incipiente. El concepto SC, como moda, pretende generar un entorno favorable para las iniciativas empresariales pero presenta problemas en la elaboración de proyectos concretos, así como en las capacidades para una transformación urbana significativa para la mejora de las condiciones de los habitantes.

En este sentido, la retórica propagandística introducida por sus impulsores se contradice con unas acciones que no están a la altura de esta publicidad. La SC realiza una promesa utópica sobre las capacidades de las nuevas tecnologías, pero la realidad muestra una estratagema estética, y estéril en resultados, donde nada cambia para el bien de la ciudadanía.

Proponer la ciudad inteligente como una alternativa revela un juego de palabras peligroso en tanto que se trabaja con una noción despolitizadora y reificante de la tecnología que trasciende las problemáticas sociourbanas. La necesidad de las ciudades para actualizarse tecnológicamente -introducida por los vendedores de estas tecnologías - refuerza la privatización de la ciudad y su vínculo con un urbanismo de corte neoliberal.

Cuando la SC supone cambios, estos no se materializan en mayores aptitudes democráticas en la gestión y el gobierno de la ciudad. La eficacia prometida en su retórica se traduce no solo en la introducción de agentes privados en la gestión de la ciudad, sino en su gobernabilidad. Es más, se han subsumido valores neoliberales - como la eficiencia-que justificarían la presencia privada en el gobierno urbano, desautorizando al ámbito público en beneficio de un sector privado enaltecido como el gobernante perfecto. Por eso, la SC no parece ser más que un modo más amigable de propagar la ideología de la ciudad neoliberal y muestra la existencia de una «nueva amalgama de poderes y prácticas corporativas y administrativas dando lugar a un esfuerzo común mucho más ambicioso que los anteriores» (Smith, 2002: 264).

13 Frase del alcade Ballesteros en AGBAR (2013). Disponible en:<http://www.agbar.es/es/comunicacion/noticias/48/jose-felix-ballesteros-en-el-futuro-todas-las-ciudades-seran-smart-o-no-seran>. 
El discurso de renovación urbana con base en la eficiencia es adoptado por unos dirigentes necesitados de grandes argumentos delante de la pérdida del desprestigio institucional y de la capacidad económica que les permitía el desarrollo urbano del pelotazo de inicios de milenio. Revelando que la SC no es tanto un programa aplicable como un mecanismo publicitario.

En este sentido, la FTSMC parece ejercer de catalizador propagandístico de los principales motores económicos de la ciudad. Así, estos mejoran su imagen poniendo el sello - y la inversión necesaria- en los diferentes proyectos del organismo.

Por otro lado, la intervención SC en Tarragona manifiesta una ausencia de programas en zonas ajenas al centro urbano. Barrios como los de Poniente no parecen incluirse como objeto de smartización, un hecho que hace peligrar la evolución de estas políticas hacia lógicas segregacionistas al desconectarse de la periferia urbana ${ }^{14}$.

En esta línea, la conectividad necesaria para la Tarragona smart city tampoco parece materializarse a nivel infraestructural. Las políticas smart no contemplarían la conexión de la ciudad con su área metropolitana, desvinculándose de la conurbación en la transformación inteligente y sin responder a cómo Tarragona se articulará mejor con el territorio.

Respecto al caso de la Tabacalera, observamos una de las problemáticas recurrentes en la ciudad posindustrial vinculada al uso del espacio industrial en desuso. El proyecto para convertir el edificio en un emblema inteligente para generar una nueva centralidad solo ha servido - a pesar de su coste: $3,3 \mathrm{M} €$ - para escenificar de manera precaria y un tanto grotesca los límites de la campaña propagandística dirigida a proyectar Tarragona como una smart city.

Nuevamente, esto nos conduce al debate sobre la gobernabilidad y el uso y la producción del espacio en la ciudad inteligente. Si el Gobierno smart tiene que ser más participativo y horizontal, ¿por qué no habilita espacios gestionados por sus habitantes como símbolo de madurez e inteligencia? ¿No se basaba, esta gobernabilidad, en responder eficazmente a las exigencias de la población?

14 Véase la ilustración 1. 
La hipotética perspectiva «ciudadana-centrista» de la ciudad inteligente, que implica la inclusión del mayor número de actores posibles en la gobernabilidad urbana (Meijer y Rodríguez Bolívar, 2016), junto con unas estructuras administrativas abiertas (Kourtit y Nijkamp, 2012), solo maximiza la presencia total de actores privados en la gobernabilidad en el caso de Tarragona.

Los desarrolladores urbanos juegan con un paradigma que no pueden, o no quieren, cumplir. Una ciudad inteligente puede traducirse en un gobierno más participativo y horizontal, tan equitativo como interseccional. Pero esta clase de premisas no encajan con la vinculación de una ciudad más abierta al capital, más neoliberal; de aquí el carácter utópico de la SC.

Como muestran los mayúsculos esfuerzos del Ayuntamiento de Tarragona, el urbanismo neoliberal, que mueve los hilos de la SC, necesita nutrirse de los beneficios que la Administración le ofrece para desplegarse. De aquí surge la contradicción más significativa que se desprende de la retórica SC: intentar ocultar que es una «expresión consumada de un urbanismo neoliberal que moviliza las demandas de la propiedad individual a través de un mercado lubricado por las subvenciones estatales» (Smith, 2002: 268).

Por otro lado, el estado actual de la Tabacalera refleja la situación de la Tarragona inteligente. El Smart Parc se ha convertido en un buque insignia vacío y en su mejor versión solo introducía una mejora de la estética en lugar de la ocupación espacial. Cuando se realizan propuestas para el uso y la apropiación espacial, la administración de la supuesta transición SC parece no estar preparada para escuchar a sus ciudadanos. La desconsideración del poder local respecto a movimientos ciudadanos como Oppida muestra cierto revanchismo al sofocar la oposición y al orientar el entorno urbano hacia intereses que no nacen de sus habitantes.

Si los JJ. MM. se fijaban entre sus objetivos el incremento de una cultura participativa, Oppida evidencia la existencia de esta cultura y la necesidad de espacios para la misma. Pese a sus intenciones teóricas, en la práctica la SC en Tarragona parece querer modificar el modelo de participación ciudadano más que aceptar el existente. 
El discurso oficial de la SC defiende una mayor participación derivada de canales virtuales, pero esta digitalización puede habilitar la desmovilización de la ciudadanía organizada. Un efecto desmovilizador vinculado a la conceptualización de la tecnología como una herramienta imparcial y liberadora perse (Rendueles, 2013). De este modo, se modifican las pautas de movilización prexistentes por fórmulas individualizadas de participación, mejor valoradas por los dirigentes políticos debido a su menor capacidad transformadora.

La SC naturaliza la idea de que la ciudad es un colectivo de actores homogéneos que ganan y pierden conjuntamente, que reciben de modo equitativo los beneficios de este hipotético nuevo urbanismo (Vanolo, 2014). Pero este eslogan evocativo no tiene que distorsionar el hecho de que la SC conlleva la intensificación de geometrías de poder que necesitan la producción y circulación de conocimiento, subjetividades y moralidades que se adapten al proyecto (Vanolo, 2014). En realidad, las visiones de la ciudad inteligente son sustitutas de visiones competitivas sobre quién tiene el poder en la sociedad (Poole, 2014).

La SC, como política de clase, integra en su retórica una suerte de bien común en un ejercicio para presentarse como un proceso natural hacia un progreso incierto, para adquirir el siguiente estadio como ciudad, como sociedad. Pero «la defensa de las estrategias de regeneración oculta tanto los objetivos como los orígenes intrínsecamente sociales de la transformación urbana, borrando la política de vencedores y vencidos de la que surgen dichas estrategias» (Smith, 2002: 267-268). Así, la principal novedad de la SC es un discurso edulcorado, dado que su contenido asume en consonancia el urbanismo neoliberal que lleva aplicándose desde los ochenta.

El escaso éxito de las iniciativas SC en Tarragona y el discutible legado post JJ. MM. que dejará esta política dan sentido al pronóstico de Datta (2015): la retórica smart descenderá, las tecnologías smart empezarán a revelar sus fracasos y la SC acabará siendo otro cliché de la historia del urbanismo global. No obstante, las aptitudes retóricas de estos proyectos no deben subestimarse, puesto que «la victoria de este lenguaje en anestesiar nuestra comprensión crítica [...] representa[ría] una considerable victoria ideológica para las visiones neoliberales de la ciudad» (Smith, 2002: 446). 


\section{Bibliografía}

ANGELIDOU, M. (2015). «Smart cities: A conjuncture of four forces». Cities, 47: 95-106.

BEANLAND, J. (2012). «London's newest development: the rise of the Ikea city». The Independent, 4: 287-322.

BORJA, J.; CASTELls, M. (1997). Local y global. La gestión de las ciudades en la era de la información. México: Taurus.

Buck, N.; While, A. (2017). «Competitive urbanism and the limits to smart city innovation: The UK Future Cities initiative». Urban Studies, 54(2): 501-519.

CAPEL, H. (2005). El modelo Barcelona: un examen crítico. Barcelona: El Serbal.

Caragliu, A.; Del Bo, C. y Nijkamp, P. (2011). «Smart cities in Europe». Journal of urban technology, 18(2): 65-82.

CAstells, M. y Hall, P. (1994). Tecnópolis del mundo: la formación de los complejos Industriales del siglo xxI. Madrid: Alianza Editorial.

DatTA, A. (2015). «A 100 smart cities, a 100 utopias». Dialogues in Human Geography, 5(1): 49-53.

DELGADO, M. (2007). La ciudad mentirosa: fraude y miseria del modelo Barcelona. Madrid: Catarata.

Dot., E.; Casellas, A. y Pallarés-Barberà, M. (2010). «Gentrificación productiva en Barcelona: efectos del nuevo espacio económico». Actas de las Cuartas Jornadas de Geografía Económica.

GARREAU, J. (1991). Edge city: Life on the new frontier. New York: Anchor.

Gibson, D. V.; Kozmetsky, G. y Smilor, R.W. (1992). The technopolis phenomenon: smart cities, fast systems, global networks. USA: Rowman \& Littlefield.

Giffinger, R.; Fertner, C.; Kramar, H.; Kalasek, R.; Pichler-Milanovic, N. y Meijers, E. (2007). «Smart cities. Ranking of European medium-sized cities, Final Report». Centre of Regional Science, Vienna UT.

Gil, O. y Navarro, C. (2013). «Innovations of Governance in Cities and Urban regions: Smart Cities in China, Iskandar (Malaysia), Japan, New York and Tarragona (Spain)». EURA Conference: Cities as Sheedbeds for Innovation (pp. 4-6). 
Glasmeier, A. y Christopherson, S. (2015). «Thinking about smart cities». Cambridge Journal of Regions, Economy and Society, 8: 3-12.

GonzÁlez Márquez, M. (2016). «Tarragona: De la bicefalía de la ciudad portuaria a la bicefalia de la ciudad postindustrial». En: LA CORRALA (coord.), Cartografia de la Ciudad Capitalista. Transformación urbana y conflicto social en el Estado Español. Madrid: Traficantes de Sueños.

Gutzmer, A. (2015). Urban Innovation Networks: Understanding the City as a Strategic Resource. London: Springer.

Harvey, D. (2001). «Globalization and the spatial fix». Geographische revue, $2(3): 23-31$.

HaRvey, D. (2013). Ciudades rebeldes: del derecho de la ciudad a la revolución urbana. Madrid: Ediciones Akal.

Harvey, D. (2003). Espacios de esperanza. Madrid: Akal.

Hollands, R. G. (2008). «Will the real smart city please stand up? Intelligent, progressive or entrepreneurial?». City, 12(3): 303-320.

Hollands, R. G. (2015). «Critical interventions into the corporate smart city». Cambridge Journal of Regions, Economy and Society, 8(1): 61-77.

JanoschKa, M. e Hidalgo, R. (2014). «La ciudad neoliberal: estímulos de reflexión crítica». En: M. Janoschka y R. Hidalgo (eds.) (2014). La ciudad neoliberal: gentrificación y exclusión en Santiago de Chile, Buenos Aires, Ciudad de México y Madrid (pp. 7-33). Chile: Serie GEOlibros.

Kitchin, R. (2015). «Making sense of smart cities: addressing present shortcomings». Cambridge Journal of Regions, Economy and Society, 8(1): 131-136.

Komninos, N. (2006). «The architecture of intelligent cities». Intelligent Environments, 6: 53-61.

Kourtit, K. y Nijkamp, P. (2012). «Smart cities in the innovation age». Innovation: The European Journal of Social Science Research, 25(2): 93-95.

Logan, J. R. y MoLotch, H. (2002) [1987]. «La ciudad como máquina de crecimiento». En: Observatorio Metropolitano de Madrid (ed.) (2002). El mercado contra la ciudad. Globalización, gentrificación y politicas urbanas (pp. 245-274).

March, H. y Ribera-Fumaz, R. (2014). «Smart contradictions: The politics of making Barcelona a Self-sufficient city». European Urban and Regional Studies, 23(4): 816-830. 
Meijer, A. y Bolívar, M. P. R. (2016). «Governing the smart city: a review of the literature on smart urban governance». International Review of Administrative Sciences, 82(2): 392-408.

Michelini, J.; TÉBAR, J. y MÉndeZ, R. (2010). «Estrategias de promoción urbana y espacios para la innovación: contrastes y contradicciones en la ciudad de Madrid». IV Jornadas de Geografía Económica, León.

Minton, A. (2012). Ground Control: Fear and happiness in the twenty-firstcentury city. United Kingdom: Penguin.

Monus (2015). Consecuencias de la realización de Macro-eventos en las ciudades-sede y sus habitantes. Bilbao: DDT Banaketak.

MuÑoz, N. (2018). «El jardín vertical y la pantalla gigante, víctimas de la dejadez». Diari de Tarragona, 9 de abril de 2018, 8-9.

Pérez Negrete, M. (2009). "Santa Fe: a "global enclave" in Mexico city». Journal of Place Management and Development, 2(1): 33-40.

Poole, S. (2014). «The truth about smart cities: 'In the end, they will destroy democracy'». The Guardian, 17 de diciembre de 2014.

Rabari, C. y Storper, M. (2014). «The digital skin of cities: urban theory and research in the age of the sensored and metered city, ubiquitous computing and big data». Cambridge Journal of Regions, Economy and Society, 8(1): 27-42.

Rendueles, C. (2013). Sociofobia. Madrid: Capitán Swing.

Servicio Público de Empleo Estatal (SEPE). (2017). Informe del Mercado de Trabajo de Tarragona, datos 2016. Catálogo general de publicaciones de la Administración General del Estado.

Smith, N. (2002). «Nuevo globalismo y nuevo urbanismo. La gentrificación como estrategia urbana global». En: Observatorio Metropolitano DE MADRID (ed.) (2002). El mercado contra la ciudad. Globalización, gentrificación y políticas urbanas (pp. 245-274).

TomÀs, M. (2015). «Gobernanza urbana y smart cities. El caso de Barcelona». En: BALCELLs, A. et alii (coords.). Actas del $11^{\circ}$ Congreso Internacional de Internet, Derecho y Política (pp. 47-59).

VANolo, A. (2014). «Smartmentality: The smart city as disciplinary strategy». Urban Studies, 51(5): 883-898. 
Washburn, D.; Sindhu, U.; Balaouras, S.; Dines, R. A.; Hayes, N. M. y NeLSON, L. E. (2010). Helping CIOs Understand 'Smart city' Initiatives: Defining the Smart city, its Drivers, and the Role of the CIO. Cambridge, MA: Forrester Research.

YigitcanlaR, T. y LeE, S. H. (2014). «Corean ubiquitous-eco-city: A smartsustainable urban form or a branding hoax?». Technological Forecasting and Social Change, 89: 100-114.

\section{Fuentes documentales}

Ajuntament de Tarragona (2011). Pla Estratègic Tarragona 2022. Tarragona. Disponible en: <http://pla2022.tarragona.cat/documents/pla_estrategic.pdf $>$.

Ajuntament de Tarragona (2012). «Tarragona Impulsa s'installa a la Tabacalera». Consultado el 28/03/2018. Disponible en: <https://www. tarragona.cat/empreses/tarragonaimpulsa/actualitat/noticies-2015/ tarragona-impulsa-sinstal.la-a-la-tabacalera>.

Ajuntament de TARRAgOna (2017a). «Bases tècniques que regiràn el concurs de redacció del projecte de desenvolupament de proposta funcional de base i proposta bàsica arquitectònica de l'equipament cultural de l'antiga Fàbrica de Tabacs. Tarragona». Disponible en: <https://goo. gl/ecAkLj>.

Ajuntament de Tarragona(2017b). Tarragona en xifres 2017. Tarragona.

Ayмi, O. (2007). «La histórica Tabacalera de Tarragona echa el cierre». El País, 24 de marzo de 2007. Consultado el 22/03/2018. Disponible en: $<$ https:// elpais.com/diario/2007/03/24/catalunya/1174702048_850215.html>.

Ballesteros, J. F. (2013). «Treballant un horitzó per Tarragona». Sala d'actes del Collegi d'Advocats i Farmacèutics de Tarragona. Tarragona, 25 de enero de 2013.

Ballesteros, J. F. (2014). «Volem i podem». Sala d'actes del Collegi d'Advocats i Farmacèutics de Tarragona. Tarragona, 28 de enero de 2014.

Centre d'Estudis Olímpics - UAB (2015). «Taula estratègica per a la dinamització econòmica i la reactivació de l'ocupació mitjançant les oportunitats generades pel llegat dels Jocs Mediterranis Tarragona 2017». Servei d'Ocupació de Catalunya. Ajuntament de Tarragona. 
FÀbregas, A. (2018). «La Tabacalera. Un edifici abandonat o en desús?». Viu a Fons, 18 de enero de 2018. Consultado el 20/03/2018. Disponible en: $<$ http://viuafons.cat/2018/01/18/la-tabacalera/>.

Filella, C. (2017). «El Museu d'Història de Tarragona també es traslladarà a la Tabacalera». El Punt Avui, 23 de febrero de 2017. Consultado el 22/03/2018. Disponible en: <http:/www.elpuntavui.cat/ cultura/article/19-cultura/1100608-el-museu-d-historia-de-tarragona-tambe-es-traslladara-a-la-tabacalera.html>.

Fundació TaRragona Smart Mediterranean City (2013). Estatuts de la fundació Tarragona 2017 Smart Mediterranean City. Àrea de Serveis Centrals, Economia i Hisenda. Tarragona.

Fundació Tarragona Smart Mediterranean City (2016). «Distinción Ciudad de la Ciencia y la Innovación, Candidatura de Tarragona». Consultado el 25/3/2018. Disponible en: <http://www.tarragonasmart.cat/mediterranean-city/wp-content/uploads/2016/12/Tarragona-Smart.pdf>.

Gebellí, N. (2017). «Autogestió a La Tabacalera». La Directa, 8 de febrero de 2017. Consultado el 22/03/2018. Disponible en: <https://directa.cat/ autogestio-tabacalera>.

GosálbeZ, C. (2017). «Ikea tendrá que esperar a principios de 2018 para iniciar las obras de su tienda». Diari Més, 30 de octubre de 2017. Consultado el 19/03/2018. Disponible en: <http://www.diarimes.com/es/ noticias/tarragona/2017/10/31/ikea_tendra_que_esperar_principios_ del_2018_para_iniciar_las_obras_tienda_27289_1091.html>.

Ponsatí, P. (2008). «Transformació urbana de la Tabacalera». Territori, observatori de projectes i debats territorials de Catalunya. Consultado el 17/3/2018. Disponible en: <http://territori.scot.cat/cat/ notices/2008/12/transformaciO_urbana_de_la_tabacalera_tarragona_2008_163.php>.

SANS, S. (2014). «Tarragona rebajará impuestos a los autónomos». La Vanguardia, 30 de enero de 2014. Consultado el 24/03/2018. Disponible en: $<$ http://www.lavanguardia.com/economia/20140130/54399714687/tarragona-rebajara-impuestos-autonomos.html>. 